\title{
Tıp Fakültesi Son Sınıf Öğrencilerinin Anafilaksi Bilgi Düzeyleri
}

\author{
Şükrü ÇEKİÇ ${ }^{1}$, Yakup CANITEZ ${ }^{1}$, Zuhal KARALI ${ }^{1}$, Berke Can KAVUKLU ${ }^{2}$, \\ İlker Gökalp GÜNEY ${ }^{2}$, Nihat SAPAN ${ }^{1}$
}

1 Bursa Uludağ Üniversitesi Tıp Fakültesi, Çocuk Alerji Bilim Dalı, Bursa.

2 Bursa Uludağ Üniversitesi Tıp Fakültesi, Bursa.

\section{ÖZET}

Anafilaksi ani gelişen ve hayatı tehdit edebilen bir aşırı duyarlılık reaksiyonudur. Erken tanı ve adrenalinin erken uygulanması mortaliteyi azaltmaktadır. Bu çalışmada tıp eğitiminin son yılında bulunan öğrencilerin anafilaksi hakkındaki bilgi düzeylerinin ölçülmesi amaçlanmıştır. Anket formu; anafilaksi etiyolojisi, tanısı, tedavisi ve korunma yöntemleri ile ilgili 14 sorudan oluşturuldu. Cevrimiçi anket formu tıp fakültesi son sınıfta bulunan 354 öğrenciye internet aracılı̆̆ıla gönderildi. Anket formu gönderilen öğrencilerin \%44,9'u (n=159) çalışmaya katıldı. Öğrencilerin kız erkek oranı 1,4 (93/66) ve ortalama yaşları $24,8 \pm 1,5$ yıl (ortanca: 25 y1l, en az: 23 , en çok: 33 ) idi. Ögrencilerin

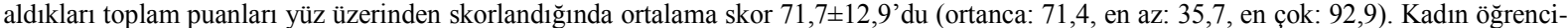
lerin ortanca skorları (ortanca: 78,6, en az: 35,7, en çok: 92,9), erkek öğrencilerden (ortanca: 71,4, en az: 35,7, en çok: 92,9) anlamlı olarak yüksekti $(\mathfrak{p}=0,011)$. Adrenalin otoenjektör uygulamasıyla ilgili eğitim aldığını ifade eden öğrencilerin ortanca skorları (ortanca: 78,6, en az: 35,7, en çok: 92,9), almadıklarını ifade edenlerden (ortanca: 71,4, en az: 35,7, en çok: 92,9) anlamlı olarak yüksekti (p<0,001). Genel olarak bakıldığında çalışmamıza katılan öğrencilerin çoğunun; anafilaksi tanısı, risk faktörleri ve tedavisi hakkındaki bilgi düzeylerinin yeterli düzeyde olduğu gözlenmiştir. Mezuniyet sonrası anafilaksi eğitimlerinin tekrarlanması mevcut durumun daha iyi hale getirilmesine ve korunmasına katkı sağlayacaktır.

Anahtar Kelimeler: Anafilaksi. Tıp fakültesi öğrencileri. Adrenalin.

Knowledge Levels of Final Year Medical School Students about Anaphylaxis

\section{ABSTRACT}

Anaphylaxis is an acute and life-threatening hypersensitivity reaction. Early diagnosis of anaphylaxis and administration of adrenaline reduces the risk of death. We aimed to measure the knowledge levels of students in the last year of medical education about the etiology, diagnosis, treatment, and prevention methods of anaphylaxis. The questionnaire form was composed of 14 questions about the etiology, diagnosis, treatment and prevention methods of anaphylaxis. An online questionnaire was sent to 354 students in the final year of medical faculty via the internet. $44.9 \%$ of the students $(\mathrm{n}=159)$ whose questionnaire was sent participated in the study. The female to male ratio of students was 1.4 (93/66) and the mean age was $24.8 \pm 1.5$ years (median 25 years, minimum: 23, maximum: 33). The mean score of participants was 71.7 \pm 12.9 (median: 71.4, minimum: 35.7, maximum: 92.9). The median scores of female students (median: 78.6, minimum: 35.7, maximum: 92.9) was significantly higher than male students (median: 71.4, minimum: 35.7, maximum: 92.9) $(p=0.011)$. The median scores of the students who stated that they were trained in adrenaline auto-injector application (median: 78.6, minimum: 35.7, maximum: 92.9) were found significantly higher than those who were not trained (median: 71.4, minimum: 35.7, maximum: 92.9) ( $<<0.001$ ). It was observed that the most of students in the final year of medical faculty who participated in our study have sufficient information about the diagnosis, risk factors, and treatment of anaphylaxis. Repeating anaphylaxis training after graduation will contribute to improving and maintaining the current situation.

Key Words: Anaphylaxis. Medical school students. Adrenaline.

Gelis Tarihi: 24.Temmuz.2020

Kabul Tarihi: 01.Ekim.2020

Dr. Nihat SAPAN

Bursa Uludağ Üniversitesi Tıp Fakültesi

Çocuk Alerji Bilim Dalı

Tel: 02242950413

E-posta: nsapan@yahoo.com.

Yazarların ORCID ID Bilgisi:

Şükrü ÇEKICC: 0000-0002-9574-1842

Yakup CANITEZ: 0000-0001-8929-679X

Zuhal KARALI: 0000-0002-4568-0121

Berke Can KAVUKLU: 0000-0003-3117-1796

İlker Gökalp GÜNEY 0000-0001-8024-9428

Nihat SAPAN: 0000-0002-7601-8392
Anafilaksi, ani gelişen ve hayatı tehdit eden bir tip 1 aşırı duyarlılık reaksiyonudur. İki binli yılların başında yaşam boyu anafilaksi prevalansının \% $0.05-2$ arasında değiştiği bildirilmiştir ${ }^{1}$. Bununla birlikte sonraki yıllarda yapılan çalışmalarda anafilaksi görülme sıklığının arttığı gösterilmiştir ${ }^{2}$. Anafilaksinin yılda her 170 çocuğun birinde meydana geldiği tahmin edilmektedir ${ }^{3}$. Çocuklarda anafilaksiye bağlı mortalite oranı erişkinlere göre daha düşüktür ${ }^{4}$. Türkiye'de çocuklarda yapılan çok merkezli bir araştırmada anafilaksiye bağlı ölüm sıklığg $1 \% 0,4$ olarak saptanmıştır ${ }^{5}$. 
Anafilaksinin erken tanınması ve adrenalinin erken uygulanması ölüm riskini önemli ölçüde azaltmaktadır ${ }^{6,7}$. Ancak, çeşitli çalışmalarda, sağlık çalışanlarının anafilaksi tanı ve tedavisiyle ilgili bilgi ve farkındalık düzeylerinin yeterli olmadığı gösterilmiştir ${ }^{8-10}$. Erken tanı ve tedavinin önemi nedeniyle anafilaksi, birinci basamak hekimleri dâhil tüm hekimlerce yeterli düzeyde bilinmelidir. Ülkemizde Mezuniyet Öncesi Tıp Eğitimi Ulusal Çekirdek Eğitim Programı'nın güncel raporunda; öğrencilerin anafilaksi konusunda acil durumu tanımlayarak ilk tedavisini yapabilecek, gerektiğinde uzmana yönlendirebilecek ve korunma önlemlerini uygulayabilecek düzeyde eğitilmeleri istenmektedir ${ }^{11}$. Çeşitli basamaklarda görev yapan hekimlerin anafilaksi bilgi düzeyleri birçok çalışmada araştırılmıştır, ancak çalışma hayatına başlamak üzere olan tıp fakültesi öğrencilerinin anafilaksi bilgi düzeylerini araştıran az sayıda çalışma vardır.

$\mathrm{Bu}$ çalışmada amacımız yakın zamanda eğitimlerini tamamlayarak birinci basamak sağlık hizmetine başlayacak son sınıf tıp fakültesi öğrencilerinin anafilaksi tanı ve tedavisiyle ilgili bilgi düzeylerini değerlendirmektir.

\section{Gereç ve Yöntem}

Çalışmaya Bursa Uludağ Üniversitesi Tıp Fakültesi 2019-2020 yılı son sınıf öğrencileri alındı. Anket soruları; tarafimızca oluşturulan sorular ve daha önce Gupta ve ark. tarafından valide edilmiş sorulardan oluşturuldu ${ }^{12}$. Anket formu Google doküman kullanılarak elektronik posta ve WhatsApp çevrimiçi uygulamaları ile öğrencilere gönderilerek, 30 dakika içinde yanıtlamaları istendi. Otuz Mayıs - 15 Haziran 2020 tarihleri arasında anket formlarını dolduran öğrencilerin sonuçları değerlendirmeye alındı.

Toplam skor 14 soruya verilen doğru yanitlar üzerinden belirlendi. Her bir soru 7.14 puan (100/14) olarak kabul edildi. Toplam skoru 60'1n üzerinde olan öğrencilerin yeterli düzeyde bilgi sahibi oldukları kabul edildi.

Çalışma için Uludağ Üniversitesi Tıp Fakültesi Klinik Araştırmalar Etik Kurulu'ndan 13.05.2020 tarih ve 2020-8/4 nolu onay alınd1.

\section{Istatistik}

Anket formlarından elde edilen veriler bilgisayar ortamına aktarılıp SPSS 23.0 (Chicago, IL, USA) programı kullanılarak istatistiksel hesaplamaları yapıldı. Çalışmada betimleyici değerler ortalama \pm standart sapma ya da ortanca (en az-en çok) olarak verildi. Niceliksel verilerin karşılaștırılmasında; ikili verilerde bağımsız örneklem için T testi ve Mann-Whitney U testi, niteliksel verilerin karşılaştırılmasında ki-kare testi kullanıldı. İstatistiksel anlamlılık seviyesi için $\mathrm{p}<0,05$ kabul edildi.

\section{Bulgular}

Davet edilen 354 öğrenciden 159'u $(\% 44,9)$ anket formlarını doldurarak çalışmaya katıldı. Çalışmaya katılan öğrencilerin k1z erkek oranı 1,4 (93/66) ve ortalama yaşları 24,8 $\pm 1,5$ yıl (ortanca 25 yıl, en az:23 yıl, en çok:33 yıl) idi. Öğrencilerin \%22'si ( $\mathrm{n}=35)$ anafilaksi vakası ile karşılaştığını ve \%27'si $(n=43)$ kendilerinde herhangi bir alerjik hastalık olduğunu bildirdi. Öğrencilerin \%33,3'ü $(n=53)$ adrenalin otoenjektör uygulamasıyla ilgili eğitim aldığını ifade ederken, \%66,7'si (n=106) almadıklarını ifade etmişlerdir.

En çok doğru yanıtlanan soru; farklı anafilaksi senaryolarından "Fıstık yeme sonrası dudaklarda ve göz kapağında şişme, hırıltı, kusma" seçeneğinin anafilaksi olduğu $(n=159, \% 100)$, en az doğru yanıtlanan soru ise Türkiye'deki adrenalin otoenjektörünün isminin sorulduğu ( $n=27, \% 17)$ sorusuydu. Ankette sorulan soruların doğru yanıtlanma oranları Tablo I'de verilmiştir.

Tablo I. Anafilaksi bilgi düzeyini ölçmek için sorulan sorular ve doğru yanıt oranları

\begin{tabular}{|c|c|}
\hline Sorular & $\begin{array}{l}\text { Doğru yanıt } \\
\text { n (\%) }\end{array}$ \\
\hline 1. Aşağıdakilerden hangisi anafilaksi değildir? & $115(72,3)$ \\
\hline $\begin{array}{l}\text { a) Arı sokması sonrası } 15 \text {. dakikada başlayan deride } \\
\text { kızarıklık, kabarıklık, hırılılı solunum }\end{array}$ & $154(96,9)$ \\
\hline $\begin{array}{l}\text { b) Penisilin alerjisi olduğu bilinen bir hastaya penisilin } \\
\text { yapıldıktan sonra sistolik tansiyonun } \% 30 \text { 'dan fazla } \\
\text { düşmesi }\end{array}$ & $154(96,9)$ \\
\hline $\begin{array}{l}\text { c) Fıstık yeme sonrası dudaklarda ve göz kapağında } \\
\text { şişme, hırıltı, kusma }\end{array}$ & $159(100)$ \\
\hline $\begin{array}{l}\text { d) Yumurta alerjisi olduğu bilinen bir hastanın yumurta } \\
\text { yedikten sonra şiddetli kusması ve cildinde kaşıntılı } \\
\text { kabarıklıklar olması }\end{array}$ & $125(77,6)$ \\
\hline $\begin{array}{l}\text { e) Süt alerjisi olan bir hastanın evde süt pişerken } \\
\text { buharından etkilenip hırıltısı olması }\end{array}$ & $115(72,3)$ \\
\hline 2. Çocuklarda en sık anafilaksi nedeni nedir? (Besinler) & $128(80,5)$ \\
\hline 3. Erişkinde en sık anafilaksi nedeni nedir? (Illaçlar) & $103(64,8)$ \\
\hline 4. Astım anafilaksi risk faktörüdür? (D) & $127(79,9)$ \\
\hline $\begin{array}{l}\text { 5. IgE ilişkili süt alerjisi olan çocuklar süt içeren yoğurt, } \\
\text { peynir yiyebilirler }(Y)\end{array}$ & $142(89,3)$ \\
\hline $\begin{array}{l}\text { 6. Fatal seyreden besin alerjilerinde ergenler, çocuklar- } \\
\text { dan daha büyük risk altındadır (D) }\end{array}$ & $62(39,0)$ \\
\hline $\begin{array}{l}\text { 7. Süt alerjisi olan çocuklar, anne sütüyle geçen madde- } \\
\text { lerle anafilaksi geçirebilirler (D) }\end{array}$ & $100(62,9)$ \\
\hline 8. Anafilakside ilk ilaç olarak adrenalin uygularım (D) & $144(90,5)$ \\
\hline $\begin{array}{l}\text { 9. Anafilaksi geçirmiş bir çocuğa adrenalin otoenjektö- } \\
\text { rü reçete ederim (D) }\end{array}$ & $138(86,8)$ \\
\hline $\begin{array}{l}\text { 10. Anafilakside adrenalin tedavisi hangi yol ile uygu- } \\
\text { lanmalıdır? (İntramüsküler) }\end{array}$ & $128(80,5)$ \\
\hline $\begin{array}{l}\text { 11. Anafilaksi tedavisinde uygulanan adrenalin dozu } \\
\text { nedir? }(0,01 \mathrm{mg} / \mathrm{kg})\end{array}$ & $120(75,5)$ \\
\hline $\begin{array}{l}\text { 12. Türkiye'deki adrenalin otoenjektörünün ismi nedir? } \\
\text { (Penepin®) }\end{array}$ & $27(17,0)$ \\
\hline $\begin{array}{l}\text { 13. Vücut ağırlığı } 33 \mathrm{~kg} \text { olan bir çocukta tercih edilen } \\
\text { otoenjektör adrenalin dozu nedir? }(0,3 \mathrm{mg})\end{array}$ & $135(84,9)$ \\
\hline $\begin{array}{l}\text { 14. Adrenalin otoenjektörünün nereye uygulanmasını } \\
\text { önerirsiniz? (Uyluk dış yan) }\end{array}$ & $128(80,5)$ \\
\hline
\end{tabular}




\section{Anafilaksi Bilgi Düzeyi}

Öğrencilerin \%90,5'i (n=144) anafilaksi tedavisinde uygulanacak ilk ilaç olarak adrenalini tercih etmiştir. Bununla birlikte ilk ilaç olarak; 8 öğrenci (\%5) intravenöz sıv1, 4 öğrenci $(\% 2,5)$ antihistaminik ve 3 öğrenci $(\% 1,8)$ metil prednizolon uygulamalarını seçmişlerdir.

Çalışmamızda tüm sorulara doğru yanıt veren öğrenci yoktu. Öğrencilerin aldıkları toplam puanları 100 üzerinden skorlandığında ortalama skor $71,7 \pm 12,9$ 'du (ortanca: 71,4, en az: 35,7, en çok: 92,9). On altı öğrencinin $(\% 10,1)$ skoru 0-50 arasında, 68 öğrencinin $(\% 42,7)$ 50-75 arasında ve 75 öğrencinin (\%47) ise 75-100 arasındaydı. Öğrencilerin \%83'ünün $(n=132)$ skoru yeterli düzey kabul edilen 60'ın üzerindeydi. Alınan puanların frekansları Şekil 1'de gösterilmiştir. Kadın öğrencilerin ortanca skorları (ortanca: 78,6, en az: 35,7, en çok: 92,9), erkek öğrencilerden (ortanca: 71,4, en az: 35,7, en çok: 92,9) anlamlı olarak yüksekti $(p=0,011)$. Adrenalin otoenjektör uygulamasıyla ilgili eğitim aldığını ifade eden öğrencilerin ortanca skorları (ortanca: 78,6, en az: 35,7, en çok: 92,9), almadıklarını ifade edenlerden (ortanca: 71,4, en az: $35,7$, en çok: 92,9$)$ anlamlı olarak yüksekti $(p<0,001)$. Daha önce anafilaksi olgusu ile karşılaşmış olanlar ve herhangi bir alerjik hastalığı olanların ortanca skorları ile olmayanlar arasında anlamlı fark saptanmadı.

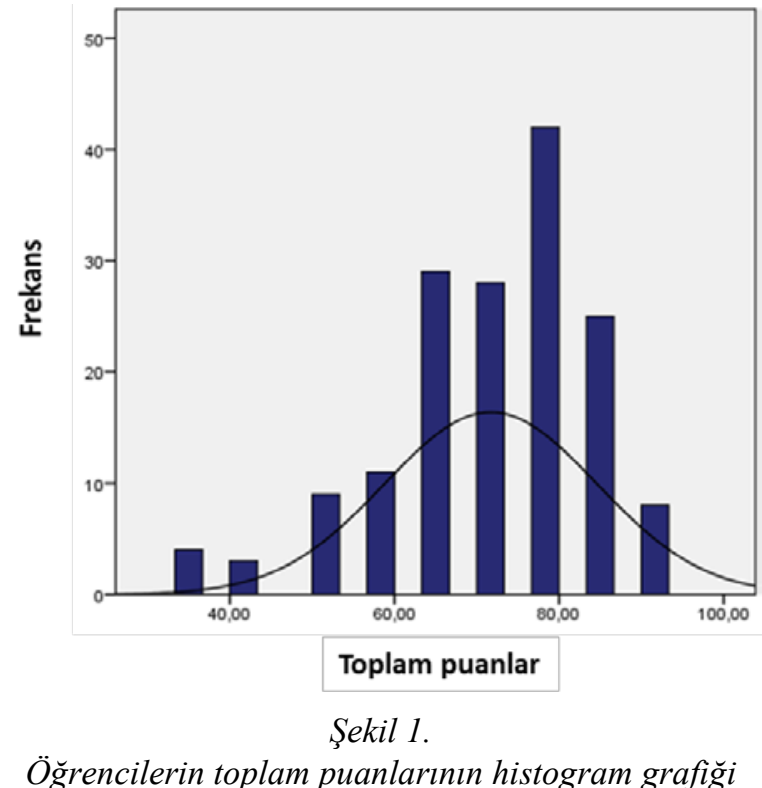

Adrenalin otoenjektörü hakkında eğitim aldığını ifade eden öğrenciler; anafilaksi yaşayan bir çocuğa otoenjektör reçete etme ( $\mathrm{n}=50, \% 94,3)$, adrenalin uygulama yolu $(n=49, \% 92,5)$, adrenalin dozu $(n=47, \% 88,7)$ ve Türkiye'deki adrenalin otoenjektörünün ismi $(n=14, \% 26,4)$ sorularına eğitim almayanlardan (sırasiyla $\mathrm{n}=88, \quad \% 83 ; \mathrm{n}=79, \quad \% 74,5 ; \mathrm{n}=73, \quad \% 68,9$; $\mathrm{n}=13, \% 12,3)$ daha yüksek oranda doğru yanıt vermişlerdir. $(p=0,047, p=0,007, p=0,006$ ve $p=0,025)$.

\section{Tartışma ve Sonuç}

Anafilaksi hızla tanınıp tedavi edilmediğinde ölüme veya ciddi komplikasyonlara neden olmaktadır ${ }^{13}$. Bu nedenle tüm basamaklarda çalışan hekimlerin anafilaksiyi tanıma ve tedavi etmede yeterli düzeyde bilgi ve beceriye sahip olması gerekmektedir. Buna karşın yapılan birçok çalışmada hekimlerin anafilaksi bilgi düzeylerinin yeterli düzeyde olmadığı tespit edilmiş$\operatorname{tir}^{8,14,15}$. Çalışmamızda 100 puan üzerinden değerlendirildiğinde tıp fakültesi 6 . Sınıf öğrencilerinin ortalama puanı 71,7 olarak bulunmuştur.

Anafilaksi tanı kriterleri birçok ulusal ve uluslararası kılavuzda birbirine benzer şekilde tanımlanmıştır ${ }^{16-18}$. $\mathrm{Bu}$ kriterler baz alınarak oluşturulan senaryolarla anafilaksi tanısı sorulduğunda doğru tanı \%77,6-100 oranlarında konulmuştur. Çalışmamızda anafilaksinin doğru tanılandırılması oranı önceki birçok çalıșmadan daha yüksek bulunmuştur ${ }^{19-21}$.

Adrenalinin hızla ve doğru uygulanması anafilaksi tedavisinin en önemli basamağını oluşturur ${ }^{16-18}$. Bununla birlikte çeşitli çalışmalarda acil servislerde anafilaksi tanısı konulsa da adrenalin yapılma oranının düşük olduğu gösterilmiştir ${ }^{22}$. Hekimlerin ve tıp fakültesi öğrencilerinin değerlendirildiği birçok çalışmada adrenalin dozu ve uygulama yolunun doğru bilinme oranının yeterli düzeyde olmadığı saptanmıştır ${ }^{9,15,23-25}$. Droste ve ark. ${ }^{10}$ tarafindan İngiltere'de 161 hekim ile yapılan bir çalışmada adrenalin uygulama yolunun doğru bilinme oranı $\% 31,1$, doğru dozun bilinme oranı ise \%15,5 olarak bildirilmiştir. Hindistan'da son sınıf tıp fakültesi öğrencileri ve hemşirelerin değerlendirildiği bir çalışmada adrenalin uygulama yolunun doğru bilinmesinin \%56,9, uygulama dozunun doğru bilinmesinin \%26,4 oranlarında bulmustur ${ }^{15}$. Gökmirza ve ark. $^{26}$ tarafından Trakya Üniversitesi Tıp Fakültesi 4., 5. ve 6. sınıf öğrencileri ile yapılan çalışmada adrenalin uygulama yolu ve dozu ile ilgili sorunun \%11 oranında doğru yanıtlandığı bildirilmiştir. Çalışmamizda ise adrenalin uygulama yolu ve dozu sirasiyla $\% 80,5$ ve $\% 75,5$ oranında doğru yanıtlanmıştır.

Çocuklarda anafilaksiye en sık besinler neden olurken erişkinlerde ilaçlar ve arı sokması ön plandadır ${ }^{27,28}$. Çalışmamızda öğrencilerin \%80,5'i çocuklarda en sık anafilaksi nedenini ve \% 64,8'i erişkinde en sık anafilaksi nedenini doğru yanıtlamışlardır.

Ölümcül anafilaksi ataklarının çoğu hastane dışında meydana geldiğinden anafilaksi riski altında olan hastalara adrenalin otoenjektörü reçete edilmesi ve kullanma yönteminin öğretilmesi son derece önemli$\operatorname{dir}^{29,30}$. Ancak gelişmiş ülkelerde yapılan çeşitli çalışmalarda da hekimlerin anafilaksi riski taşıyan hastalarda adrenalin otoenjektörü yazma oranının düşük olduğu gösterilmiştir ${ }^{31,34}$. Amerika Birleşik Devletleri'nde yapılan bir çalışmada anafilaksi nedeniyle başvuran hastaların sadece \%63'üne adrenalin otoenjektö- 
rü reçete edildiği gösterilmiștir ${ }^{35}$. Ülkemizde farklı iki merkezde yapılan çalışmalarda bu oran $\% 7,4$ ve \%8,1 olarak bildirilmiştir ${ }^{14,32}$. Çalışmamızda ise öğrencilerin $\% 86,8^{\prime} \mathrm{i}$ anafilaksi yaşayan çocuğa adrenalin otoenjektörü yazacaklarını belirtmişlerdir, bu oranın yüksek bulunması anafilaksi uzun dönem yönetiminde yüz güldürücüdür.

Penepin hâlihazırda ülkemizdeki tek adrenalin otoenjektörüdür. Ülkemizde yapılan çeşitli çalışmalarda hekimlerin adrenalin oto-enjektörün ismini bilme oranı \%20,3-28 olarak bulunmuştur ${ }^{8,26,36}$. Çalışmamızda ise öğrencilerden yalnızca \%17'si adrenalin oto-enjektörünün ticari ismini doğru bilmiştir. Gerek bizim çalışmamızın sonuçları gerekse önceki çalışmalar, hekimler arasında adrenalin otoenjektörü hakkındaki farkındalığın artırılması gerektiğini göstermektedir. Adrenalin otoenjektörü varlığından ve isminden haberdar olmanın reçete edilmesini kolaylaştıracağını düşünüyoruz.

Çalışmamızda andrenalin otoenjektörü hakkında eğitim aldığını ifade eden öğrenciler; adrenalin otoenjektörü reçete etme, adrenalin uygulama yolu, adrenalin dozu ve Türkiye'deki adrenalin otoenjektörünün ismi sorularına eğitim almayanlardan daha yüksek oranda doğru yanıt vermişlerdir. Bu durum adrenalin otoenjektörü hakkındaki eğitiminin anafilaksi yönetiminde ve takibinde önemini ortaya koyan çalışmaları desteklemektedir ${ }^{26,37}$.

Astım şiddetli ve ölümcül anafilaksi için risk faktörüdür $^{38,39}$. Çalışmamızda öğrencilerin $\% 79,9$ 'u astımın anafilaksi için risk faktörü olduğu sorusunu doğru yanıtlamıştır.

Daha yüksek risk alma kapasiteleri, ebeveyn ya da bakıcı denetimi azlığı ve daha düşük sorumluluk düşüncesi gibi nedenlerle ergenler fatal anafilaksi için daha yüksek risk altındadır ${ }^{40}$. Çalışmamızda öğrencilerin \%39'u ergenlerin fatal seyreden besin alerjilerinde çocuklardan daha yüksek riske sahip oldukları ile ilgili soruyu doğru yanıtlamışlardır. Bu oran daha önceki çalışmalarda; birinci basamak sağlık hizmeti veren hekimler, aile hekimleri ve pediatristler tarafindan verilen doğru yanıt oranlarıyla benzerdir ${ }^{13,14}$.

Birinci basamak sağllk hizmeti veren hekimlerin değerlendirildiği bir çalışmada katılımcıların $\% 37,5^{\prime} \mathrm{i}$ süte karşı alerjisi olan çocukların süt ürünlerini serbest bir şekilde tüketip tüketemeyecekleri ile ilgili soruya doğru yanıt vermişlerdir ${ }^{14}$. Çalışmamızda ise benzer soruyu öğrencilerin \%89,3'ü doğru yanıtlamıştır. $\mathrm{Bu}$ durumun, besin alerjilerinin toplumda artan skklıkları ile paralel olarak daha sık vurgulanması ile ilişsili olabileceğini düşünüyoruz.

Genel olarak bakıldığında çalışmamıza katılan son sınıf tıp fakültesi öğrencilerinin; anafilaksi tanısı, risk faktörleri ve tedavisi hakkındaki bilgi düzeylerinin yeterli seviyede olduğu gözlenmiștir. Bu sonucun; anafilaksinin görülme sıklığındaki artışla birlikte, eğiticilerin anafilaksi tanı ve tedavisinin önemi konusunda daha vurgulayıcı olmaları ve öğrencilerin anafilaksi hakkındaki farkındalıklarının artmasıyla ilişkili olabileceğini düşünüyoruz. Mezuniyet sonrası anafilaksi eğitimlerinin tekrarlanması bu seviyenin korunmasını ve yükseltilmesini sağlayacaktır.

Etik Kurul Onay Bilgisi:

Onaylayan Kurul: Uludağ Üniversitesi Tıp Fakültesi Klinik Araştırmalar Etik Kurulu.

Onay Tarihi: 13.05 .2020

Karar No: 2020-8/04

\section{Kaynaklar}

1. Lieberman P, Camargo CA Jr, Bohlke K et al. Epidemiology of anaphylaxis: findings of the American College of Allergy, Asthma and Immunology Epidemiology of Anaphylaxis Working Group. Ann Allergy Asthma Immunol 2006;97:596-602.

2. Tejedor Alonso MA, Moro Moro M, Mugica Garcia MV et al. Incidence of anaphylaxis in the city of Alcorcon (Spain): A population-based study. Clin Exp Allergy 2012; 42:578-589

3. de Silva IL, Mehr SS, Tey D et al. Paediatric anaphylaxis: a 5year retrospective review. Allergy 2008;63:1071-1076

4. Turner PJ, Gowland MH, Sharma V et al. Increase in anaphylaxis-related hospitalizations but no increase in fatalities: an analysis of United Kingdom national anaphylaxis data, 1992- 2012. J Allergy Clin Immunol 2015;135:956

5. Orhan F, Canitez Y, Bakirtas A et al. Anaphylaxis in Turkish children: a multi-centre, retrospective, case study. Clin Exp Allergy 2011;41:1767-1776,

6. Sheikh A, Shehata YA, Brown SG et al. Adrenaline for the treatment of anaphylaxis: cochrane systematic review. Allergy 2009; 64:204

7. Simons FE. Emergency treatment of anaphylaxis. BMJ 2008; 336:1141

8. Baccioglu A, Ucar EY. Level of knowledge about anaphylaxis among health care providers. Tuberk Toraks 2013;61:140-146.

9. Jose R, Clesham GJ. Survey of the use of epinephrine (adrenaline) for anaphylaxis by junior hospital doctors. Postgrad Med J 2007;83:610-611.

10. Droste J, Narayan N. Hospital doctors' knowledge of adrenaline (epinephrine) administration in anaphylaxis in adults is deficient. Resuscitation 2010;81:1057-1058.

11. Mezuniyet Öncesi Tıp Eğitimi Ulusal Çekirdek Eğitim Program1 2020 https://tip.uludag.edu.tr/sites/default/files/egitimprogramlari/cep-2020.pdf

12. Gupta RS, Springston EE, Kim JS et al. Food allergy knowledge, attitudes, and beliefs of primary care physicians. Pediatrics. 2010 ;125(1):126-132.

13. Drupad HS, Nagabushan H. Level of knowledge about anaphylaxis and its management among health care providers. Indian J Crit Care Med. 2015;19(7):412-415.

14. Erkoçoğlu M, Civelek E, Azkur D, et al. Knowledge and attitudes of primary care physicians regarding food allergy and anaphylaxis in Turkey. Allergol Immunopathol (Madr) 2013;41:292-297.

15. Haymore BR, Carr WW, Frank WT. Anaphylaxis and epinephrine prescribing patterns in a military hospital: underutilization of the intramuscular route. Allergy Asthma Proc 2005;26:361365.

16. Muraro A, Werfel T, Hoffmann-Sommergruber $\mathrm{K}$ et al; EAACI Food Allergy and Anaphylaxis Guidelines Group. EAACI food 


\section{Anafilaksi Bilgi Düzeyi}

allergy and anaphylaxis guidelines: diagnosis and management of food allergy. Allergy.2014;69(8):1008-25.

17. Simons FE, Ardusso LR, Bilò MB et al. World Allergy Organization. World allergy organization guidelines for the assessment and management of anaphylaxis. World Allergy Organ J 2011;4(2):13-37.

18. Orhan F, Civelek E, Şahıner ÜM ve ark. Anafilaksi: Türk Ulusal Rehberi 2018. Asthma Allergy Immunol 2018;16:1-62.

19. Özkars MY. Anaflaksiye Aile Hekimlerinin Gözünden Bakış. JCP2019;17:(1):34-44.

20. Munblit D, Treneva M, Korsunskiy I et al. A national survey of Russian physicians' knowledge of diagnosis and management of food induced anaphylaxis. BMJ Open 2017; 7(7):e015901.

21. Krugman SD, Chiaramonte DR, Matsui EC. Diagnosis and management of food-induced anaphylaxis: a national survey of pediatricians. Pediatrics 2006;118:554-560.

22. Prince BT, Mikhail I, Stukus DR. Underuse of epinephrine for the treatment of anaphylaxis: missed opportunities. J Asthma Allergy 2018;20;11:143-151.

23. Bernstein DI, Wanner M, Borish L et al. Twelve-year survey of fatal reactions to allergen injections and skin testing: 1990 2001. J Allergy Clin Immunol 2004;113:1129-1113.

24. Gompels LL, Bethune C, Johnston SL et al. Proposed use of adrenaline (epinephrine) in anaphylaxis and related conditions: a study of senior house officers starting accident and emergency posts. Postgrad Med J 2002;78:416-418.

25. Thain S, Rubython J. Treatment of anaphylaxis in adults: results of a survey of doctors at Dunedin Hospital, New Zealand. N Z Med J 2007;120:1-8.

26. Gokmirza P, Beken B, Celik V, Yazicioglu M, Sut N.Future doctors and anaphylaxis: What do they know? What should we do? Annals of Medical Research 2019;26(10):2340-2345.

27. Grabenhenrich LB, Dolle S, Moneret-Vautrin A et al. Anaphylaxis in children and adolescents: The European Anaphylaxis Registry. J Allergy Clin Immunol 2016;137:11281137.

28. Oropeza AR, Bindslev-Jensen C, Broesby-Olsen S et al. Patterns of anaphylaxis after diagnostic workup: A follow-up study of 226 patients with suspected anaphylaxis. Allergy 2017;72(12):1944-1952
29. Simons FER, Ebisawa M, Sánchez-Borges M et al. 2015 update of the evidence base: World Allergy Organization anaphylaxis guidelines. World Allergy Organ J 2015;8(1):32.

30. Lieberman P, Nicklas RA, Randolph C et al. Anaphylaxis-a practice parameter update 2015. Ann Allergy Asthma Immunol 2015;115(5):341-384.

31. Sidhu N, Jones S, Perry T, et al. Evaluation of anaphylaxis management in a pediatric emergency department. Pediatr Emerg Care 2016;32(8):508-513.

32. Gelincik A, Demirtürk M, Y1lmaz E et al. Anaphylaxis in a tertiary adult allergy clinic: a retrospective review of 516 patients. Ann Allergy Asthma Immunol 2013;110(2):96-100.

33. Campbell RL, Luke A, Weaver AL et al. Prescriptions for selfinjectable epinephrine and follow-up referral in emergency departmentpatients presenting with anaphylaxis. Ann Allergy Asthma Immunol 2008;101(6):631-636.

34. Prince BT, Mikhail I, Stukus DR. Underuse of epinephrine for the treatment of anaphylaxis: missed opportunities. J Asthma Allergy. 2018;11:143-151.

35. Russell WS, Farrar JR, Nowak R et al. Evaluating the management of anaphylaxis in US emergency departments: Guidelines vs. practice. World J Emerg Med 2013;4(2):98-106.

36. Cetinkaya F, Zübarioğlu AU, Göktaş S. Pediatricians' knowledge about recent advances in anaphylaxis treatment in Istanbul, Turkey. Turk J Pediatr 2009;51(1):19-21.

37. Arga M, Bakirtas A, Turktas I et al. Do pediatricians and the pediatric residents know how to use adrenalin autoinjector? Asthma Allergy Immunol 2009;7:26-31.

38. Calvani M, Cardinale F, Martelli A et al. Italian and members Members of the Italian Society of Pediatric Allergy and Immunology (SIAIP) Anaphylaxis' Study Group. Risk factors for severe pediatric food anaphylaxis in Italy. Pediatr Allergy Immunol 2011;22:813-819.

39. González-Pérez A, Aponte Z, Vidaurre CF, Rodríguez LA. Anaphylaxis epidemiology in patients with and patients without asthma: a United Kingdom database review. J Allergy Clin Immunol. 2010;125(5):1098-1104.e1.

40. Marques ML, Gouveia J, Cunha I M et al. Anaphylaxis in pediatric age: an overview. Nascer e Crescer - Birth And Growth Medical Journal 2020;29(2):92-100. 
